\title{
Giving radiologists a voice: a review of podcasts in radiology
}

Christopher G. D. Clarke ${ }^{1^{*}} \mathbb{D}$, Uzoma Nnajiuba², Jamie Howie ${ }^{2}$, Muhammad Khan², Daniel Pinto dos Santos ${ }^{3}$ and Erik Ranschaert ${ }^{4}$

\begin{abstract}
Objectives: Podcasts are audio recordings distributed via the Internet. We review the availability of podcasts on the topic of radiology.

Methods: A search for podcasts relating to radiology was performed using search engines and free public websites that either hosted or distributed podcasts. Only English language podcast series were included, and video podcasts were excluded. Data was gathered by manually interrogating the metadata on the primary hosting platform and related websites.

Results: Forty-one podcast series met the inclusion criteria. The earliest was from 2005. In total, 56.1\% of podcasts were defined as active and $43.9 \%$ inactive at the time of publication. Number of episodes for each podcast series ranged from 1 to 269 with $56.1 \%$ of podcasts having $\leq 10$ episodes. There was a wide variation in podcast series' frequency/schedules. The most common subject topic was 'radiology current affairs' (43.9\%), with the least common 'exam revision' (7.3\%) and 'radiography' (7.3\%). The majority of podcasts were targeted at radiologists (87.8\%) and originated from the USA (70.1\%). Podcast hosts consisted of doctors (63.4\%), other professionals (29.3\%) or unknown (7.3\%). Additional supplementary media or information as show notes were provided by $26.8 \%$ of radiology podcast series.
\end{abstract}

Conclusions: This gives a new insight into the world of 'radiology podcasting'. To the authors' knowledge, this is the first review in the literature and highlights the increasing availability of podcasting in radiology.

Keywords: Radiology podcast, Social media, Podcasts

\section{Key points}

- Podcasts provide a novel means for radiology focused educational content.

- There are a varied and growing number of radiology podcasts.

\section{Introduction}

Podcasts are audio recordings distributed via the Internet and available to download or stream on smartphones, tablets, portable devices and personal computers without payment. A podcast episode is a single audio recording, and multiple episodes under the same umbrella

\footnotetext{
* Correspondence: christopher.clarke@nuh.nhs.uk

${ }^{1}$ Department of Radiology, Nottingham University Hospitals NHS Trust, Derby Road, Nottingham NG7 2UH, UK

Full list of author information is available at the end of the article
}

title make up a podcast series. Users typically subscribe to podcasts via podcast apps to allow automatic downloading of new episodes. They are convenient as they may be listened to on almost any Internet-enabled device such as smartphones, computers and smart speakers, at any time, for example, whilst doing other activities such as driving [1].

There has been rapid growth in the awareness of podcasting with an estimated $70 \%$ of the US population now familiar with this term [2]. An estimated 32\% of Americans (age 12+) listen to a podcast every month in 2019, compared with $9 \%$ in 2008 [2]. This percentage was higher in younger listeners with an estimated $40 \%$ of those aged $12-24$ and $39 \%$ of those aged $25-54$ listening to at least one podcast each month [2]. Much of this growth is believed to be driven by smartphone use [3]. 
In 2019, 93\% of podcast listeners listened to either 'most of' or the entire podcast episode [1].

Some podcasts are published along with 'show notes' which may include a written transcript of the audio, links to resources and other supplementary information. Podcasts require minimal technical knowledge to create and may be of high quality using a microphone and audio editing software, but may also be recorded and created using a smartphone [4].

The aim of this article is to review the availability of podcasts on the topic of radiology.

\section{Material and method}

\section{Identification of podcast series}

All information was sourced from free public websites that either hosted or distributed podcasts.

To ensure a comprehensive search of available free podcasts, a search was performed using the search term 'radiology' on 10 podcast hosting platforms: Anchor, Apple Podcasts/iTunes, Spotify, Google Podcasts, Podbean, Overcast, Stitcher, Breaker, Castbox and RadioPublic (Table 1).

An additional search in Google using the search term 'radiology podcast' was performed, and the first 10 result pages were explored to look for any additional podcasts not identified by our initial search and ensure as comprehensive a search as possible. It is not possible to guarantee that every eligible podcast series has been included in this study as podcasts are a decentralised medium and there is no single exhaustive database. However, we hope that by looking at multiple different hosting platforms and sources, that our search is more extensive than similar studies which have used the 'iTunes podcast directory' as the primary source for data collection [5].

\section{Inclusion and exclusion criteria}

To ensure only valid podcast series were included, stringent inclusion and exclusion criteria were set as follows:

Table 1 Web addresses for each hosting platform searched

\begin{tabular}{ll}
\hline Hosting platform & Web address (URL) \\
\hline Anchor & https://anchor.fm \\
Apple Podcasts/iTunes & https://www.apple.com/uk/itunes/podcasts \\
Spotify & https://www.spotify.com \\
Google Podcasts & https://podcasts.google.com \\
Podbean & https://www.podbean.com \\
Overcast & https://overcast.fm \\
Stitcher & https://www.stitcher.com \\
Breaker & https://www.breaker.audio \\
Castbox & https://castbox.fm \\
RadioPublic & https://radiopublic.com \\
\hline
\end{tabular}

- The overarching theme of the podcast series must be radiology. Podcast series with episodes related to radiology, but where radiology was not the primary theme of the whole series were excluded.

- Podcasts hosted solely on paid-for subscription platforms were excluded.

- Video podcasts, also called 'vodcasts', were excluded. A vodcast is defined as a podcast that contains video content. If a video podcast had a separate pure audio offering, then this was included.

- Only English language podcast series were included.

\section{Data collection and categorisation}

On 12 October 2019, the authors collected various information relating to each podcast series as summarised in Table 2. Data was gathered by manually interrogating the visual and textual 'metadata' relating to each podcast series on the primary hosting platform and related websites, e.g. social media pages. Where necessary, the audio content of the podcast series was also listened to by the authors to obtain required information that was not included in this visual and textual metadata such as the name of a particular podcast host. It was not necessary to contact any individuals directly associated with the podcasts to obtain any of the data required. All data was manually coded and categorised by the authors. The associated supplementary database contains specific dates of when information pertaining to each podcast was gathered.

\section{Statistical analysis}

All data relating to the podcast series and subsequent categorisation was recorded in a spreadsheet (Google Sheets), and basic descriptive and categorical analysis was undertaken within the spreadsheet. The figures were created using Google Sheets and R 3.6.1 (R Core Team (2019). R: A language and environment for statistical computing. R Foundation for Statistical Computing, Vienna, Austria. URL https://www.R-project.org/).

\section{Results}

Forty-one podcast series met the inclusion criteria for the study (Table 3). The earliest radiology podcast started in 2005 , and at the time of writing, there were 10 new radiology podcasts in 2019. Twenty-three of the 41 podcast series $(56.1 \%)$ were defined as active, meaning that they had released an episode within the immediate 6 months prior to our search. Eighteen of the 41 podcast series (43.9\%) were inactive. Some podcast series had been inactive for longer than others (range 195-3811 days). Overall, there was a steady increase in the total number of podcasts and active podcasts over time (Fig. 1). Interestingly, there were a large number of new podcasts within the last 12 months $(n=12)$. 
Table 2 Information collected for each podcast series along with description/definition

\begin{tabular}{|c|c|}
\hline Information & Description/definition \\
\hline Podcast title & Title given by the podcast authors on website or hosting site. \\
\hline Subject category & $\begin{array}{l}\text { We devised four categories into which we classified the various podcast series based on common subject matter. } \\
\text { These were as follows: } \\
\text { - Journal podcast—-podcasts affiliated with a peer reviewed journal or in which the review of journal articles was } \\
\text { the subject matter. } \\
\text { - Exam revision—-podcasts intended specifically to be used as a revision resource for a named radiology exam. } \\
\text { - Educational_-podcasts aimed at educating listeners, but not directly related to exam revision or affiliated with a } \\
\text { peer reviewed journal. } \\
\text { - Radiology current affairs_-podcasts that discuss issues relevant to clinical radiology. } \\
\text { - Radiography—podcasts intended for radiographers (radiologic technologists). }\end{array}$ \\
\hline Network/affiliation & Organisation, institution and/or body affiliated with the podcast series. \\
\hline Hosts & $\begin{array}{l}\text { The host/interviewer for the podcast series was categorised as one of the following: } \\
\text { - Named host(s) } \\
\text { - Anonymous (host not named) } \\
\text { - Various (no regular host, e.g. if the podcast series consisted of presentations rather than interview/discussion format) }\end{array}$ \\
\hline Number of hosts & $\begin{array}{l}\text { Number of hosts/interviewers per podcast series (guests not included). If the number of interviewers/speakers varies, } \\
\text { then 'variable' is stated. }\end{array}$ \\
\hline Country & Name of the country primarily associated with the podcast. \\
\hline Show notes & $\begin{array}{l}\text { Supplementary media or information on the podcast episodes available to audiences via podcast apps or related } \\
\text { websites (if present). Show notes may include images, videos, hyperlinks, scientific references and audio transcripts; } \\
\text { however, simple descriptions of a podcast episode are not classified as 'show notes'. }\end{array}$ \\
\hline First episode & Date the first published episode was available to stream or download. \\
\hline Most recent episode & Date the most recent published episode was available to stream or download. \\
\hline Lifetime & Duration between the first episode becoming available to stream or download, and the most recent episode. \\
\hline Sampling date & Date on which data was collected. \\
\hline Number of episodes & Total number of episodes available to stream or download in the podcast series to date. \\
\hline Frequency schedule & $\begin{array}{l}\text { Regularity with which podcast episodes are released. If there was a slight variation between podcast releases, } \\
\text { then an average schedule was determined at the discretion of the author: } \\
\text { - Weekly_once a week } \\
\text { - Fortnightly_two episodes every month } \\
\text { - Monthly_once a month } \\
\text { - Quarterly_once every } 3 \text { months } \\
\text { - Sporadic-no pattern of regularity } \\
\text { - Undetermined_insufficient episodes to determine frequency }\end{array}$ \\
\hline Status & $\begin{array}{l}\text { Whether podcast is active or inactive. Definitions are as follows: } \\
\text { - Active-most recent episode released within } 6 \text { months ( } 180 \text { days) of sampling date. } \\
\text { - Inactive-no episodes released for } 6 \text { months ( } 180 \text { days) prior to the sampling date. }\end{array}$ \\
\hline Website & Address of website or dedicated section/page on the network/organisation website dedicated to the podcast (if present). \\
\hline Twitter & Twitter account or network/organisation Twitter account which promotes the podcast content (if present). \\
\hline Facebook & Facebook account or network/organisation Facebook account which promotes the podcast content (if present). \\
\hline Email & Is a contact email address provided for the podcast? \\
\hline
\end{tabular}

The number of episodes released by each podcast series was highly variable ranging from 1 to 269 episodes. The average number of episodes per month over the lifetime of each podcast series (time from the first podcast episode to the most recent podcast episode) ranged from 0.2 to 8 (Fig. 2). 56.1\% of podcasts had 10 episodes or fewer, and $17 \%$ had 50 episodes or more. The mean number of episodes was 30.1 , and the median was 9 .

There was a wide variation in podcast series' frequency/schedules (Fig. 3), with most podcasts published on a sporadic basis; 4 were weekly, 6 fortnightly, 6 monthly, 0 quarterly, 21 sporadic and 4 undetermined as there were insufficient episodes to determine frequency.

When grouped by subject category, most podcast series were on the topic of 'radiology current affairs' (43.9\%), followed by 'educational' (22\%), 'journal podcast' (19.5\%), 'exam revision' (7.3\%) and 'radiography' (7.3\%). Figure 4 shows the number of podcast series in each category and whether active or inactive.

The vast majority of radiology podcasts were targeted at radiologists $(87.8 \%)$ with three targeted at radiographers and students $(7.3 \%)$, one at data scientists $(2.4 \%)$ and one at healthcare companies $(2.4 \%)$. 
Table 3 Summary of radiology podcast series (data sampled 12 October 2019)

\begin{tabular}{|c|c|c|c|c|c|}
\hline Podcast title & Category & Affiliation & Country & $\begin{array}{l}\text { Number of } \\
\text { episodes }\end{array}$ & $\begin{array}{l}\text { Active/ } \\
\text { inactive }\end{array}$ \\
\hline 5 Minute Radiography & Radiography & None & USA & 8 & Inactive \\
\hline A Look Inside & Educational & None & USA & 2 & Inactive \\
\hline Advances in Medical Imaging & $\begin{array}{l}\text { Radiology } \\
\text { current affairs }\end{array}$ & Reach MD & USA & 22 & Inactive \\
\hline $\begin{array}{l}\text { Advancing Clinical Research Quibim } \\
\text { Podcast }\end{array}$ & $\begin{array}{l}\text { Radiology } \\
\text { current affairs }\end{array}$ & Quibim & USA & 9 & Inactive \\
\hline AJNR Podcasts & $\begin{array}{l}\text { Journal } \\
\text { podcast }\end{array}$ & American Journal of Neuroradiology & USA & 227 & Active \\
\hline British Institute of Radiology Podcasts & $\begin{array}{l}\text { Radiology } \\
\text { current affairs }\end{array}$ & British Institute of Radiology & UK & 58 & Active \\
\hline Capitol Radiology & Educational & Capital Radiology & Australia & 2 & Inactive \\
\hline Cassling Academy & $\begin{array}{l}\text { Radiology } \\
\text { current affairs }\end{array}$ & None & USA & 5 & Active \\
\hline Clinical Correlation Required & Educational & None & USA & 3 & Inactive \\
\hline Clinical PET Cast & Educational & None & USA & 50 & Inactive \\
\hline Clinical Radiology & $\begin{array}{l}\text { Journal } \\
\text { podcast }\end{array}$ & Royal College of Radiology & UK & 30 & Active \\
\hline CTisus & $\begin{array}{l}\text { Radiology } \\
\text { current affairs }\end{array}$ & None & USA & 66 & Inactive \\
\hline Diagnostic Imaging & $\begin{array}{l}\text { Radiology } \\
\text { current affairs }\end{array}$ & Modern Medicine Network & USA & 21 & Inactive \\
\hline $\begin{array}{l}\text { Diffusion - A quick radiology podcast by } \\
\text { Bhavin Jhankaria }\end{array}$ & Educational & None & India & 1 & Active \\
\hline EuSoMII on AIR & $\begin{array}{l}\text { Radiology } \\
\text { current affairs }\end{array}$ & $\begin{array}{l}\text { European Society of Medical Imaging } \\
\text { Informatics }\end{array}$ & Austria & 4 & Active \\
\hline Exploring the Horizon & $\begin{array}{l}\text { Radiology } \\
\text { current affairs }\end{array}$ & None & Belgium & 9 & Active \\
\hline$J V I R$ & $\begin{array}{l}\text { Journal } \\
\text { podcast }\end{array}$ & $\begin{array}{l}\text { Journal of Vascular and Interventional } \\
\text { Radiology }\end{array}$ & USA & 89 & Active \\
\hline Meaningful Use In Radiology & $\begin{array}{l}\text { Radiology } \\
\text { current affairs }\end{array}$ & Carestream & USA & 5 & Inactive \\
\hline Medical Imaging Matters & $\begin{array}{l}\text { Radiology } \\
\text { current affairs }\end{array}$ & $\begin{array}{l}\text { The Association for Medical Imaging } \\
\text { Management }\end{array}$ & USA & 2 & Active \\
\hline Medscape Radiology Podcast & $\begin{array}{l}\text { Radiology } \\
\text { current affairs }\end{array}$ & Medscape & USA & 45 & Inactive \\
\hline Men In Lead Aprons & Educational & Center for Radiological Research & USA & 10 & Inactive \\
\hline More Programs in Radiology & $\begin{array}{l}\text { Radiology } \\
\text { current affairs }\end{array}$ & University of California Television & USA & 24 & Active \\
\hline Philips Healthcare Talks & $\begin{array}{l}\text { Radiology } \\
\text { current affairs }\end{array}$ & Philips & USA & 6 & Inactive \\
\hline Philips Imaging Connections & $\begin{array}{l}\text { Radiology } \\
\text { current affairs }\end{array}$ & Philips & USA & 3 & Active \\
\hline $\begin{array}{l}\text { Pro Tips on How to Write Outstanding } \\
\text { Radiology Letters of Recommendation }\end{array}$ & Educational & Writeperfect LTD & Cyprus & 1 & Active \\
\hline R25 & $\begin{array}{l}\text { Journal } \\
\text { podcast }\end{array}$ & $\begin{array}{l}\text { NYU Langone Medical Center in New York } \\
\text { City }\end{array}$ & USA & 6 & Inactive \\
\hline RadCast & $\begin{array}{l}\text { Radiology } \\
\text { current affairs }\end{array}$ & None & UK & 18 & Active \\
\hline Radiographics Podcasts & $\begin{array}{l}\text { Journal } \\
\text { podcast }\end{array}$ & Radiological Society of North America & USA & 39 & Active \\
\hline Radiology Firing Line & $\begin{array}{l}\text { Journal } \\
\text { podcast }\end{array}$ & $\begin{array}{l}\text { Journal of the American College of } \\
\text { Radiology }\end{array}$ & USA & 61 & Active \\
\hline
\end{tabular}


Table 3 Summary of radiology podcast series (data sampled 12 October 2019) (Continued)

\begin{tabular}{|c|c|c|c|c|c|}
\hline Podcast title & Category & Affiliation & Country & $\begin{array}{l}\text { Number of } \\
\text { episodes }\end{array}$ & $\begin{array}{l}\text { Active/ } \\
\text { inactive }\end{array}$ \\
\hline Radiology Podcasts & $\begin{array}{l}\text { Journal } \\
\text { podcast }\end{array}$ & Radiological Society of North America & USA & 269 & Active \\
\hline RadProfPodcast & Educational & None & USA & 1 & Inactive \\
\hline Rapids by Songs 4 FRCR & Exam revision & None & UK & 1 & Inactive \\
\hline RLI Taking the Lead Podcast & $\begin{array}{l}\text { Radiology } \\
\text { current affairs }\end{array}$ & American College of Radiology & USA & 34 & Active \\
\hline Rural Radiology Journal club & $\begin{array}{l}\text { Journal } \\
\text { podcast }\end{array}$ & $\begin{array}{l}\text { Australia and New Zealand Rural } \\
\text { Radiology Special Interest Group }\end{array}$ & $\begin{array}{l}\text { Australia and New } \\
\text { Zealand }\end{array}$ & 2 & Inactive \\
\hline SIIMcast & $\begin{array}{l}\text { Radiology } \\
\text { current affairs }\end{array}$ & $\begin{array}{l}\text { Society for Imaging Informatics in } \\
\text { Medicine }\end{array}$ & USA & 33 & Active \\
\hline $\begin{array}{l}\text { Songs } 4 \text { FRCR: Radiology FRCR } \\
\text { 2A Revision }\end{array}$ & Exam Revision & None & UK & 25 & Active \\
\hline The FRCR 2B Podcast & Exam revision & $\begin{array}{l}\text { Imperial College Radiology Training } \\
\text { Scheme }\end{array}$ & UK & 6 & Active \\
\hline The Hounsfield Unit & Educational & None & USA & 2 & Active \\
\hline The Radiologic Technologist Podcast & Radiography & None & USA & 2 & Active \\
\hline The Sound of IR Podcast & $\begin{array}{l}\text { Radiology } \\
\text { current affairs }\end{array}$ & None & USA & 26 & Active \\
\hline The Topics in Radiography Podcast & Radiography & None & USA & 9 & Inactive \\
\hline
\end{tabular}

When we looked at the country primarily associated with each podcast series, the majority originated from the USA (70.1\%), followed by the UK (14.6\%) then Australia/New Zealand (4.9\%) followed by Austria (2.4\%), Belgium (2.4\%), Cyprus (2.4\%) and India (2.4\%).

Additional supplementary media or information as show notes were provided by $26.8 \%$ of radiology podcast series radiology podcast series in the form of article links
(17.1\%), podcast transcripts $(9.8 \%)$, revision notes $(4.9 \%)$ and videos $(2.4 \%)$. Two podcasts provided both article links and podcast transcripts (those published by the Radiological Society of North America).

$36.6 \%$ of podcasts were hosted by radiologists, $12.2 \%$ by radiologists in training (junior doctors/residents), $12.2 \%$ by doctors outside of radiology, $12.2 \%$ by radiographers, $2.4 \%$ by a medical student, and $17.1 \%$ by other

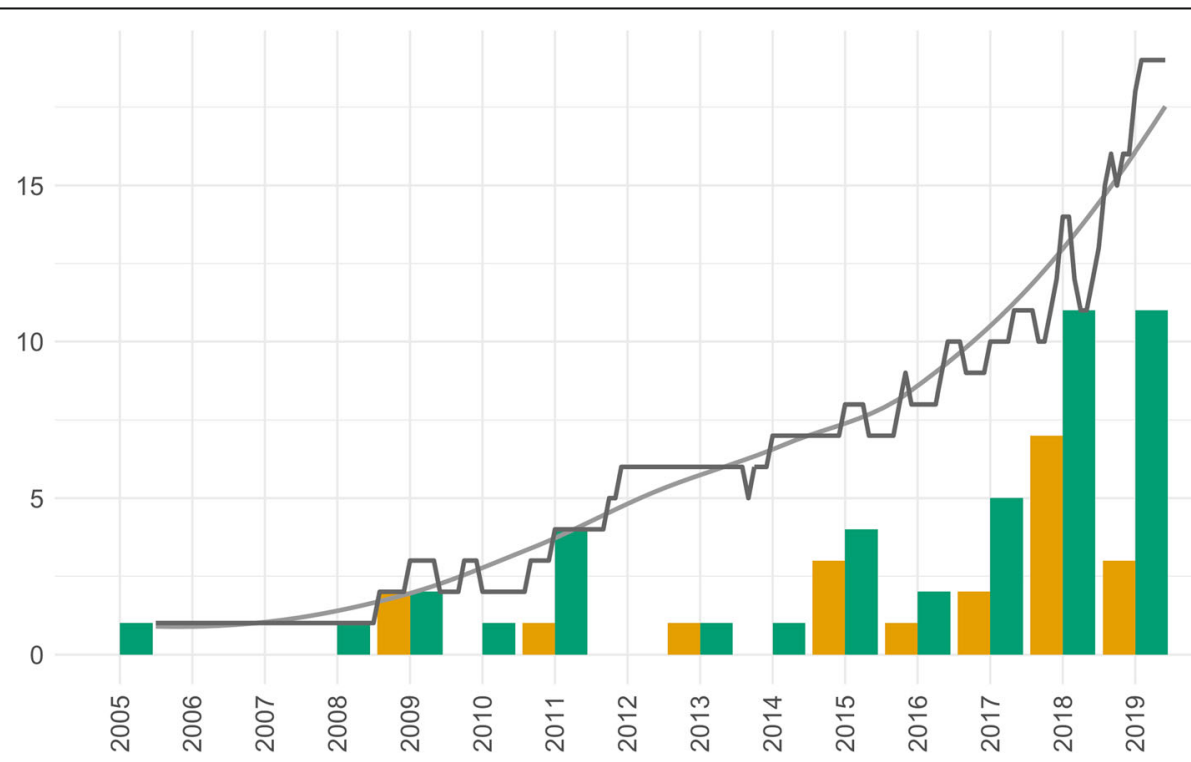

Fig. 1 Development of podcasts over time. The black line shows the total number of active podcast series (y-axis) by year ( $x$-axis). The bar chart shows the number of podcast series started (green) and discontinued (orange) in each year. The graph shows that the total number of podcasts has risen steadily over the last 14 years, with a more rapid increase in the number of new podcasts over the last 2 years 


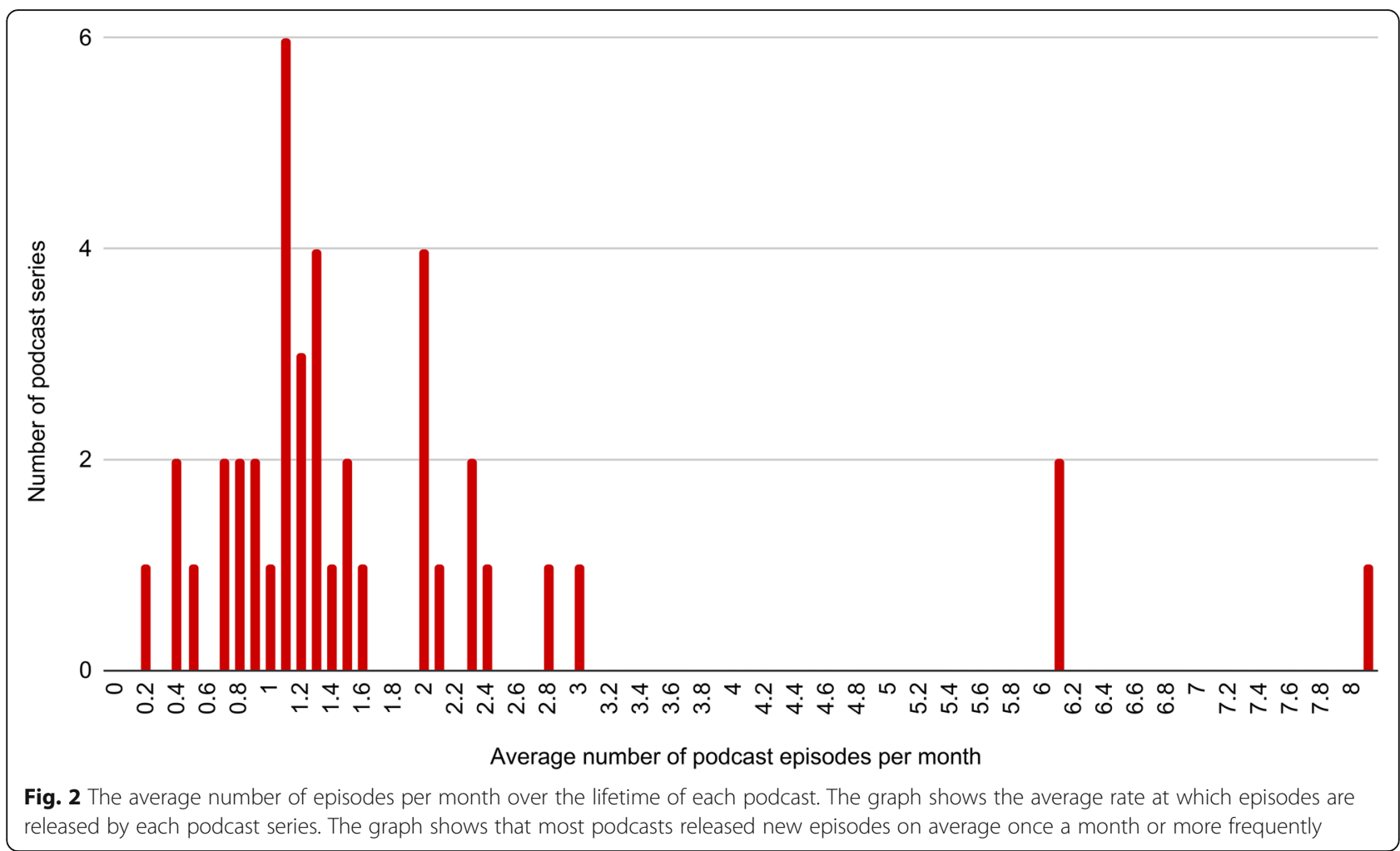

professionals (content development manager, senior counsellor, academic, corporate director/president), and in $7.3 \%$, the host regularly changed and it was unknown who the host was. $85.4 \%$ had a single interviewer/host, and $14.6 \%$ had more than one host/ interviewer.

\section{Discussion}

To the authors' knowledge, this is the first time radiology podcasts have been analysed in the literature and this gives a new insight into the world of 'radiology podcasting'. The authors searched the PubMed database, and no similar review papers could be found.

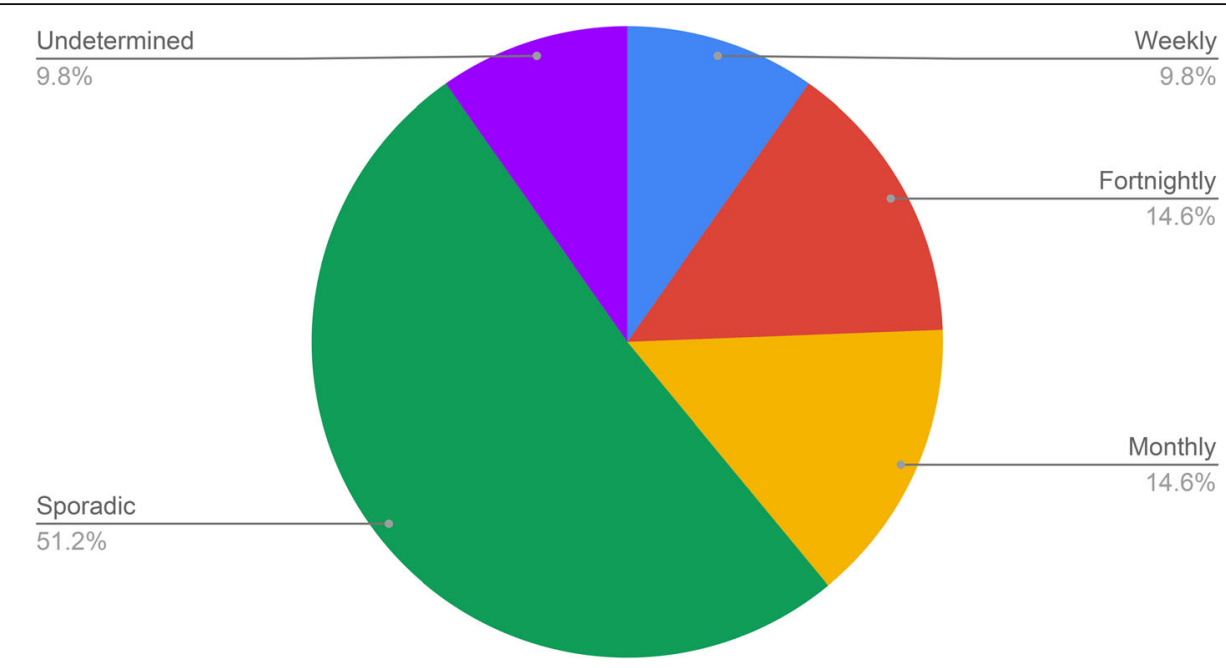

Fig. 3 Podcast series' frequency/schedule. The pie chart shows the distribution of scheduling of new podcast episodes for each podcast series. The largest proportion sampled were sporadic (51.2\%), followed by monthly and fortnightly (both 14.6\%), then weekly and undetermined (both 9.8\%) 


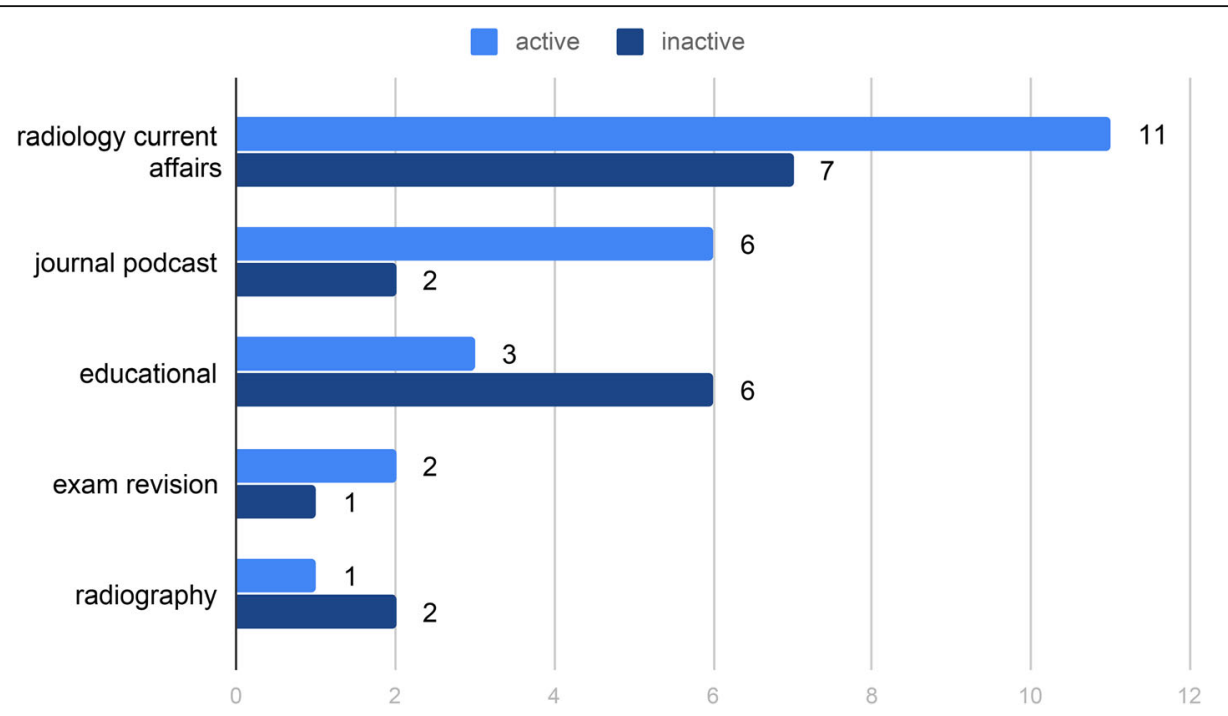

Fig. 4 Podcast series by category and whether active or inactive. A bar chart showing the number of podcast series in each subject category and whether active or inactive.

Podcasting usage has shown a steady increase over time [2]. There are now over 700,000 active podcasts with over 29 million podcast episodes [6]. As can be seen above, a significant number of radiology-related podcasts are already available on a range of platforms. There is currently no detailed data available on the age or demographics of the audience reached by those radiology-related podcasts; however, data from the general podcasting suggest that the vast majority of listeners should fall in the 25-44 years of age group and be almost equally distributed with respect to gender [6]. With that in mind, it would only seem logical that most radiology-related podcasts currently focus on content that is relevant to this target group and features either specific educational material or topics that may be of special interest to an audience at the beginning or in the early middle of their career.

Outside of radiology, among the genres most listened to, educational podcasts are currently the second most listened to genre, surpassed only by comedy podcasts [7]. Therefore, it is interesting to note that of the nine educational podcasts in our study, only three remain active. We cannot be sure of the reason for this, but there are many factors to consider such as 'educational' in the general setting may include journal podcasts and other scientific podcasts, which we categorised separately in our paper. The high proportion of inactive podcasts is reflective of a wider phenomenon across all podcast genres known as 'podfade'. This is when a podcast ceases to publish new episodes [8]. In a 2015 semi-formal nonpeer-reviewed study looking at all podcasts on iTunes US, Morgan found that only $40 \%$ of podcasts were active (had released an episode in the last 6 months) [9]. In 2019, MacKenzie, looking specifically at science podcasts, found only $46 \%$ to be active (had released an episode in the last 3 months) [5]. Our study found that overall $56.1 \%$ of radiology podcasts were active which is in line with the literature and indicates the difficulty of maintaining a podcast series. Reasons for podfade include loss of passion, lack of time, loss of a co-host and major life events [10]. We also hypothesise that the hosts of the educational podcasts may have stopped producing episodes because they progressed in their careers and the original aim of the podcast (such as for exam revision, for example) was no longer relevant to them, or that maybe they lacked funding for the podcast since usually there is no reimbursement unless sponsored by a company or a society.

Although some could argue that educational activities requiring dedicated attention such as reading a book or listening to a live lecture could have a more lasting effect, some studies suggest that the retention rate is relatively high from purely auditory learning [7]. It also seems that podcast listeners listen to podcasts in a way that allows for multitasking whilst listening. This is reflected by the results of a recent survey which suggested that a significant percentage of users listen to podcasts whilst driving (52\%), commuting on public transport (37\%), travelling (46\%) or even during workout (32\%) [7]. A recent qualitative study on a medical podcast found that the podcast was perceived to increase efficiency and permit users to multitask by using mobile platforms [11]. Interestingly, surveys also found that almost a fifth of all 
podcast listeners increased the speed of the podcast to be able to listen to it faster [6].

The authors feel that the 'radiology podcasts' from RSNA deserves a special mention since they have produced a continuous programme of podcasts for over 10 years and the highest number of radiology podcasts so far with 269 episodes. The host is David Bluemke (editor of Radiology), and the authors felt the quality was high with topics well-selected, which could be explained by the fact that the content is related to the content of the journal, which is one of the most highly ranked radiology journals [12]. As well as interesting summaries of latest journal articles, they also interview authors and we feel this is an excellent example of what a radiology podcast can be.

Despite not meeting our inclusion criteria, we feel the podcast series 'Professor Hallux' also deserves an honourable mention due to its novelty. This is a podcast produced by the educational and entertainment website FunKidsLive.com, designed to educate children on the human body. As part of a collaboration with the Royal College of Radiologists (UK), they produced a ten-part series called 'Looking Inside the Human Body' to introduce children to radiology. Episodes included 'Who's who in radiology', 'How ultrasound works' and 'The science behind radiation'. As this was only a short run of episodes within a much larger series unrelated to radiology, it was judged not to meet our inclusion criteria and excluded from our results.

Although the authors tried their best to obtain highquality data, it is important to note the limitations of this study. Firstly, there is no single directory within which all podcasts can be found. Therefore, although we tried to be as comprehensive as possible, it is still possible that there are eligible podcasts that have not been included in our study. Given the extent of our search, however, it is unlikely that an eligible podcast not included in our study would be found by a member of the target audience. Secondly, only podcasts in the English language were assessed, so there may be radiology podcasts in other languages which we have not included. Thirdly, podcast episode length and statistics on the number of downloads were not publically available. This data would have been useful to gain a more complete analysis of the use and proliferation of radiology podcasts. We did not formally evaluate the quality of individual podcasts or analyse the motivations for podcast hosts to create these podcasts, and other than the presence of show notes, we did not look into how the various podcasts used social media or other websites to engage with audiences. In several cases, the identity of the podcast presenter(s) and their credentials were not openly declared, and so this was difficult to ascertain. This poses a problem as listeners may be receiving information from non-credible or unverifiable sources. In such cases, we were also unable to analyse the authors motivation for hosting the podcast and scrutinise for conflicting interests.

To conclude, this study is the first to look at the phenomenon of 'radiology podcasts' and shows that there are an increasing number of radiology podcasts with a large number of new podcasts in the last 12 months, with the majority targeted at radiologists. The reasons behind this increase were not assessed; however, it fits with the trend of growing use of podcasting in general. Further research regarding the profile of the podcast audience, the listener motivation and experience, and the most appreciated type of content for radiology podcasts would be valuable for optimising usage of this medium.

\section{Authors' contributions}

CC conceptualised the manuscript, wrote the introduction and was a major contributor in writing the manuscript. UN, JH and MK analysed and interpreted the podcast data and were major contributors in writing the manuscript. DS wrote much of the discussion and was a major contributor in writing the manuscript. ER was a major contributor in writing the manuscript. All authors read and approved the final manuscript.

\section{Funding}

The authors state that this work has not received any funding.

Availability of data and materials

All data is publicly available and can be obtained by following the steps as specified in the 'Material and method' section.

Ethics approval and consent to participate

Not applicable.

Consent for publication

Not applicable.

Competing interests

UN, JH, and MK produce the RadCast podcast (https://www.radiologycafe. com/radcast).

ER produces the EUSOMII podcast (https://anchor.fm/eusomii) and Exploring the Horizon podcast (https://anchor.fm/erik-ranschaert). The other authors declare that they have no competing interests.

\section{Author details}

'Department of Radiology, Nottingham University Hospitals NHS Trust, Derby Road, Nottingham NG7 2UH, UK. ²Department of Radiology, Aintree University Hospital NHS Foundation Trust, Liverpool L9 7AL, UK. ${ }^{3}$ Department of Radiology, Faculty of Medicine and University Hospital, University of Cologne, Kerpener Str. 62, 50937 Cologne, Germany. ${ }^{4}$ Department of Radiology, Elisabeth-TweeSteden Ziekenhuis, Hilvarenbeekseweg 60, 5022 GC Tilburg, The Netherlands.

\section{Received: 12 November 2019 Accepted: 30 January 2020}

\section{References}

1. (2019) The Podcast Consumer 2019. In: Edison Res. https://www. edisonresearch.com/the-podcast-consumer-2019/. Accessed 14 Sept 2019

2. (2019) The Infinite Dial 2019. https://www.edisonresearch.com/wp-content/ uploads/2019/03/Infinite-Dial-2019-PDF-1.pdf. Accessed 25 Mar 2019

3. The Nielsen Company (US) A Marketer's Guide to Podcasting Q1 2018 https://www.nielsen.com/content/dam/corporate/us/en/reportsdownloads/2018-reports/marketeres-guide-to-podcasting-march-2018.pdf. Accessed 26 May 2019 
4. Anchor - The best way to make your podcast. In: Anchor. https://anchor. $\mathrm{fm} /$. Accessed 25 Mar 2019

5. MacKenzie Lewis E (2019) Science podcasts: analysis of global production and output from 2004 to 2018. R Soc Open Sci 6:180932. https://doi.org/10. 1098/rsos.180932

6. Whitner G (2019) Podcast Statistics (2019) - [Infographic]. In: Music Oomph. https://musicoomph.com/podcast-statistics/. Accessed 9 Nov 2019

7. Leadem R (2017) The Growth of Podcasts and Why It Matters (Infographic). In: Entrepreneur. https://www.entrepreneur.com/article/3 06174. Accessed 25 Mar 2019

8. Niemeyer L (2018) How to Predict the Death of a Podcast. The what, how, and why of the "podfade" phenomenon. In: Medium. https://bellocollective. com/the-death-of-a-podcast-the-what-how-and-why-of-podfade-568f6 ae7322c. Accessed 18 Jan 2020

9. Morgan J (2015) How Podcasts Have Changed in Ten Years: By the Numbers. In: Medium. https://medium.com/@monarchjogs/how-podcasts-havechanged-in-ten-years-by-the-numbers-720a6e984e4e. Accessed 18 Jan 2020

10. McGivern A (2015) What is Podfading? | Definition of Podfade. In: Podcast Hero. https://www.podcasthero.com/what-is-podfading-definition-ofpodfade/. Accessed 18 Jan 2020

11. Malecki SL, Quinn KL, Zilbert N et al (2019) Understanding the Use and Perceived Impact of a Medical Podcast: Qualitative Study. JMIR Med Educ 5: e12901 https://doi.org/10.2196/12901

12. About Radiology. https://pubs.rsna.org/page/radiology/about. Accessed 8 Feb 2020

\section{Publisher's Note}

Springer Nature remains neutral with regard to jurisdictional claims in published maps and institutional affiliations.

\section{Submit your manuscript to a SpringerOpen ${ }^{\circ}$ journal and benefit from:}

- Convenient online submission

- Rigorous peer review

- Open access: articles freely available online

- High visibility within the field

- Retaining the copyright to your article

Submit your next manuscript at $\boldsymbol{\nabla}$ springeropen.com 